\title{
ANALYSIS OF TISSUE BIOPSY AND JOINT ASPIRATION IN THE DIAGNOSIS OF PERIPROSTHETIC HIP INFECTIONS: CROSS-SECTIONAL STUDY
}

\author{
ANÁLISE DA BIÓPSIA DE TECIDOS PERIARTICULARES E DO \\ ASPIRADO ARTICULAR NO DIAGNÓSTICO DE INFECÇÕES \\ PERIPROTÉTICAS DO QUADRIL: ESTUDO TRANSVERSAL
}

\author{
Elton Andreolla ${ }^{1}$ (i), Marco Bernardo Cury Fernandes ${ }^{1}$ (i), Carla Ormundo Gonçalves Ximenes Lima ${ }^{1}$ (i), \\ augusto Carlos Maciel Saraiva ${ }^{1}$ (1)
}

1. Instituto Nacional de Traumatologia e Ortopedia, Rio de Janeiro, RJ, Brazil.

\section{ABSTRACT}

Objective: To evaluate sensitivity, specificity, accuracy, positive predictive value, and negative predictive value of preoperative joint aspiration (PJA) and periarticular tissue percutaneous biopsy (PTPB), as well as their combination, in the diagnosis of infection after total hip arthroplasty. Methods: This cross-sectional study (Level of Evidence II) was conducted with prospective data on 29 patients submitted to PJA with PTPB at the National Institute of Orthopedics and Traumatology from September 2015 to January 2016. Specimens obtained during the procedures underwent microbiological analyses, and the results were compared with those obtained in subsequent revision arthroplasty surgeries. Results: PJA, PTPB, and their combination reached values of $78 \%, 73 \%, 89 \%$ for sensitivity, respectively; $72 \%, 90 \%, 94 \%$ for specificity; and 76\%, 80\%, 90\% for accuracy. Conclusions: PJA combined with PTPB was sensitive, specific, and effective in diagnosing periprosthetic hip infection. Level of Evidence II, Prospective Cross-Sectional Study

Keywords: Hip Arthroplasty. Injections, Intra-Articular. Liquid Biopsy. Diagnosis. Infection.

\section{RESUMO}

Objetivo: Avaliar a sensibilidade, especificidade, acurácia, valor preditivo positivo e valor preditivo negativo dos métodos diagnósticos aspirado articular pré-operatório (AAPO), biópsia percutânea de tecidos periarticulares (BPTP) e ambos associados na infecção pós-artroplastia total de quadril (IPATQ). Métodos: Trata-se de um estudo transversal (Nível de Evidência II) com coleta prospectiva de dados obtidos de 29 pacientes submetidos a AAPO com BPTP no Instituto Nacional de Ortopedia e Traumatologia durante o período de setembro de 2015 à janeiro de 2016. Foram comparados os resultados das análises microbiológicas dos espécimes obtidos por meio da BPTP e do AAPO com os obtidos intraoperatoriamente nas cirurgias subsequentes de revisão das artroplastias. Resultados: Encontramos uma sensibilidade da AAPO, BPTP e ambos, respectivamente de 78\%, 73\%, 89\%, uma especificidade de $72 \%$, 90\%, 94\% e uma acurácia de 76\%, 80\%, 90\%. Conclusões: 0 procedimento de AAPO com BPTP para diagnóstico de infecção periprotética de quadril é sensível, específico e eficaz. Nível de Evidência II, Estudo Transversal Prospectivo.

Descritores: Artroplastia de Quadril. Injeções Intra-Articulares. Biópsia Líquida. Diagnóstico. Infecção.

Citation: Andreolla E, Fernandes MBC, Lima COGX, Saraiva ACM. Analysis of tissue biopsy and joint aspiration in the diagnosis of periprosthetic hip infections: cross-sectional study. Acta Ortop Bras. [online]. 2021;29(5):242-245. Available from URL: http://www.scielo.br/aob.

\section{INTRODUCTION}

Infection is a common cause of failure in joint replacement surgery, with $7 \%$ to $16 \%$ of revision hip arthroplasties (RHA) accounting for it. ${ }^{1}$ The incidence of infections after total hip arthroplasty (IATHA) decreased by $1-2 \%$ in international reference centers during recent years, ${ }^{2}$ but Brazil lacks well-established statistics on this condition.
Many of these infections are hidden, with no active fistula nor obvious clinical signs, presenting as prosthetic loosening, osteolysis, or pain without specific cause. ${ }^{3}$

Thus, an accurate preoperative diagnosis of IATHA is essential in patients with radiological signs of prosthetic loosening and hip pain after arthroplasty. ${ }^{4}$ However, diagnosing IATHA in cases without clear signs and active fistulas can be difficult, especially before the lack of a diagnostic method with high specificity and sensitivity. ${ }^{5}$ Tests

All authors declare no potential conflict of interest related to this article.

The study was conducted at the Instituto Nacional de Traumatologia e Ortopedia (INTO).

Correspondence: Elton Andreollla. Rua Colombia, 203, sala 01 e 02, Caçador, SC, Brazil, 89500178. elton.a@unochapeco.edu.br

Article received on 08/05/2020, approved on 10/09/2020. 
such as C-reactive protein (CRP) and erythrocyte sedimentation rate (ESR) are indirect markers of infection and/or inflammation, but they have low specificity for the diagnosis of IATHA. ${ }^{6-8}$

Preoperative joint aspiration (PJA) is one of the diagnostic methods for IATHA, with sensibility ranging from $50 \%$ to $86 \%$ and specificity from $88 \%$ to $96.1 \% .^{2,9,10}$ When associated with periarticular tissue percutaneous biopsy (PTPB) before revision surgery, PJA reaches higher sensitivity (80\% to $83 \%$ ), specificity (90\% to $100 \%$ ), accuracy ( $97 \%$ to $87.9 \%$ ), and positive predictive values (73.8\% to $100 \%) ., 6$ However, some factors limit their diagnostic performance, hindering or even precluding the identification of the causative agent of IATHA, such as prior antibiotic use, biofilm, and the lack of joint fluid..$^{11}$

The test considered gold standard for identifying the pathogen of these infections includes the culture of five or six periprosthetic samples (joint aspirate and tissue fragments) collected during $\mathrm{RHA}$, whereby the presence of two or more positive specimens with isolation of the same infectious agent is considered as IATHA. Most studies addressing PJA and PTPB compare their diagnostic value using this method. ${ }^{6,11,12}$

Up to date, no studies have been conducted in the national scenario investigating the diagnostic value of these two procedures in suspected cases of IATHA. Thus, this study aims to (1) estimate the diagnostic values of PJA, PTPB, and their association, using the culture of articular fluid and tissue fragments extracted during subsequent RHA as gold standard; (2) compare the sensitivity of the PTPB procedure with that of PJA; (3) correlate our results on sensitivity with those reported in other studies; and (4) describe the complications associated with these procedures.

\section{MATERIALS AND METHODS}

This is a cross-sectional study conducted with prospective data on patients submitted to PJA with PTPB at the National Institute of Orthopedics and Traumatology (INTO) from September 2015 to January 2016. All patients included in the study had scheduled RHA surgery, either due to aseptic failure or suspected septic failure. Specimens obtained during PJA and PTPB underwent microbiological analyses, and the results were compared with those obtained in subsequent RHA.

Exclusion criteria consisted of (1) acute infection less than four weeks postoperatively; (2) patients who underwent antibiotic therapy within two weeks prior to $\mathrm{RHA}$; (3) patients who did not agree to participate in the study; (4) gross contamination of the collected material; (5) time interval greater than two hours between collection and processing of clinical specimens.

All patients provided written informed consent (ICF) during hospitalization for PJA and BPTP, prior to any of the study procedures. The study was approved by the Research Ethics Committee of the INTO under opinion number 1285647, CAAE 49261115.400005273.

The association between PJA with PTPB is a routine procedure at INTO's Hip Specialized Care Center, involving percutaneous sample collection of joint aspirate and four periprosthetic tissue fragments with the aid of fluoroscopy. This procedure was performed under sterile conditions in the operating room, through the anterolateral route of the hip, using Jamshid needle and with the aid of image intensifier. ${ }^{13}$ All patients were submitted to spinal anesthesia.

If no fluid was aspirated, saline solution at $10 \mathrm{~mL}$ was instilled in the hip joint and aspirated again - as proposed by Ali et al..$^{10}$ and Williams et al. ${ }^{9}$ Two specimens of periacetabular periprosthetic tissue and two specimens of femoral periprosthetic tissue were collected. All samples were placed in a sterile tube with fluid thioglycollate medium and referred for analysis at the Laboratory of Anaerobic Biology of the Universidade Federal do Rio de Janeiro (UFRJ) while kept at room temperature, being processed within two hours after collection. Solid specimens received approximately ten sterile glass beads and were submitted to the vortex at $40 \mathrm{~Hz}$ for 15 seconds. ${ }^{14}$ The resulting pasty material was inoculated in three blood agar plates, supplemented with hemine and menadione (ASS) and chocolate agar. For each medium, one plate was incubated in one type of atmosphere: capnophile $\left(3-5 \% \mathrm{CO}_{2}\right.$ and $\left.12-17 \% \mathrm{O}_{2}\right)$, anaerobiosis (anaerobic jar and/or chamber, containing 10\% CO2, 10\% hydrogen, and $80 \%$ nitrogen) and aerobiosis (35-37 ${ }^{\circ} \mathrm{C}$ greenhouse). Moreover, $1 \mathrm{~mL}$ of the vortex-resulting material for each specimen was inoculated in anaerobic brain-heart infusion (BHI) medium in an inoculator table. Solid media, thioglycollate, and $\mathrm{BHI}$ were observed for 14 days and subcultured in case of liquid medium turbidity. Media presenting no growth after this time were discarded and the culture considered negative.

Bacterial identification was performed using the Matrix Assisted Laser Desorptionlonization - Time of Flight (MALDI-TOF) technology, based on the profile of most abundant proteins specific to each microorganism. One or two recent colonies were applied on a Maldi plate, forming a thin film over which $2 \mu \mathrm{L}$ of a saturated $\alpha$-cyano-4-hydroxycinnamic matrix solution (50\% acetonitrile, $2.5 \%$ trifluoroacetic acid) was deposited. After air-drying, the plate was inserted into the equipment for reading.

During RHA surgery, aspirated joint fluid and four tissue specimens were collected from sites suggestive of periprosthetic infection and submitted to the transport and microbiological analysis procedures described above. After sample collection, positive cases for PJA and PTPB underwent systemic transoperative antibiogram-based antibiotic therapy, whereas those without preoperative positive result underwent antibiotic prophylaxis (cefazolin 2g EV).

Cases presenting growth of the same microorganism in at least two of the five specimens were considered as positive for IATHA, either for those obtained by PJA+PTPB or those obtained during RHA. As supported by Virolainen et al., ${ }^{15}$ cases with bacterial growth in a single specimen were deemed as contamination.

Clinical and demographic data underwent descriptive analysis by calculating median, variation (minimum-maximum), and proportions. Considering the results of the culture of intraoperatively collected samples as gold standard, values of sensitivity (true positive - TP/[TP + false negatives - FN]) and specificity (true negatives - TN)/[false positives - FP + TN]), as well as positive predictive value - PPV (TP/[TP+ FP]) and negative predictive value - NPV (TN/[FN + TN]) of PTPB and PJA were calculated. Diagnostic accuracy was calculated by the sum of TP and TN divided by the number of tests performed. Sensitivity values of PJA used in isolation and combined with PTPB were compared using the McNemar's test. For statistical analysis, 95\% confidence intervals and $p$-values were calculated, with $p$-values lower than 0.05 being considered significant.

Data were tabulated in the Microsoft Excel (Windows 8 version), and all analyses were performed using SPSS for Windows (version 10.0; SPSS, Chicago, IL, USA).

\section{RESULTS}

Of the 32 patients eligible to participate in the study, three were excluded for being using antibiotics at the time of the proposed procedure. Thus, our sample included 29 patients and 30 PJA+PT$\mathrm{PB}$, as one patient underwent the procedure in both hips. Of these, 18 were males (62\%) and 11 females (38\%) with mean age of 58 years (36-81 range). All patients agreed to participate by signing the informed consent form. 
We identified fifteen TP cases, eight TN, three FP, and four FN for PJA. As for PTPB, we verified 14 TP, 10 TN, one FP, and five FN. By assessing the combination of the two procedures (PJA + PTPB), we identified the following:

The diagnostic value of the combined procedure (PJA + BPTP) was higher than that found for each procedure in isolation.

Before the inability of obtaining pure joint fluid, we had to instill saline solution in four cases according to the protocol - none of which corresponded to the false positives and negatives identified among the sample.

According to the criteria described in the methodology section, no tissue or aspirate sample was contaminated in PJA+PTPB or RHA. We identified 11 different microorganisms in patients who tested positive for infection (Table 1). Except for false positives, microorganisms identified in PJA and PTPB also grew in RHA in positive cases, with the Staphylococcus haemolyticus being the most prevalent microorganism in all procedures (21.2\%).

Table 1. Microorganisms identified in positive cases of infection after total hip arthroplasty submitted to periarticular tissue percutaneous biopsy, preoperative joint aspiration, and revision hip arthroplasty.

\begin{tabular}{c}
\hline Identified microorganisms \\
\hline Pseudomonas aeruginosa \\
\hline Staphylococcus epidermidis \\
\hline Propionibacterium acnes \\
\hline Staphylococcus capitis \\
\hline Staphylococcus haemolyticus \\
\hline Micrococcus/uteus \\
\hline Acinetobacter baumannii \\
\hline Klebsiella pneumoniae \\
\hline Streptococcusgallolyticus \\
\hline Enterococcus faecium \\
\hline Enterobacter cloacae
\end{tabular}

We observed no complications due to PTPB, such as vascular and nerve lesions or needle path infection.

\section{DISCUSSION}

As surgical planning differs in the presence of infections, one must rule out infections after total hip arthroplasty (IATHA) before submitting a patient to revision hip arthroplasty (RHA). Moreover, knowing the infective microorganism beforehand allows the surgeon to determine the antibiotic to be added to the prosthetic cement used in the RHA, besides assisting in the decision of performing the revision surgery in one or two stages. When compared to other less effective and noninvasive methods such as inflammatory markers and imaging tests, obtaining periprosthetic specimens in the preoperative period of RHA has gained prominence in the guidelines for diagnosing IATHA. However, the contribution of preoperative joint aspiration (PJA) and periarticular tissue percutaneous biopsy (PTPB) when performed in isolation is still a controversial subject and little studied in the national scenario.

In our study, the PJA + PTPB method showed a sensitivity of $89 \%$ higher than that reported in the literature, ranging from $80 \%$ to $83 \%$. The association also presented good specificity $(90 \%)$, negative predictive value (NPV; 83\%), positive predictive value (PPV; 94\%), and accuracy $(90 \%)$. These values are similar to those found in the literature, which show specificity from $94 \%$ to $100 \%$, PPV from $74 \%$ to $100 \%$, and accuracy from $88 \%$ to $97 \%$. $^{9,12,16}$ (Table 2).

\begin{tabular}{c|c|c|c}
\multicolumn{4}{|c}{ Table 2. Diagnostic values of the procedures performed. } \\
\hline & PJA & PTPB & PJA+PTPB \\
\hline Sensitivity (95\% Cl) & $78 \%(54-93)$ & $73 \%(48-90)$ & $89 \%(66-98)$ \\
\hline Specificity (95\% Cl) & $72 \%(39-93)$ & $90 \%(58-99)$ & $90 \%(58-99)$ \\
\hline PPV (95\% Cl) & $83 \%(58-96)$ & $93 \%(68-99)$ & $94 \%(72-99)$ \\
\hline NPV (95\% Cl) & $66 \%(34-90)$ & $66 \%(38-88)$ & $83 \%(51-97)$ \\
\hline Accuracy & $76 \%$ & $80 \%$ & $90 \%$ \\
\hline
\end{tabular}

The higher sensitivity found in our study may be explained by the differentiated microbiological process used, with up to 14 days of incubation period for specimen cultures, rapid transport in culture medium, anaerobic incubation, and the use of the vortex to release bacteria adhered onto biofilm. . $^{7-9,12}$

Most studies on PJA and PTPB either do not report incubation period or adopt an unappropriate period, besides waiving the use of vortex in samples processing. According to the literature, culture time should extend for more than seven days in cases of suspected periosteosynthetic infection, and reach up to 14 days in suspected periprosthetic hip infections. ${ }^{7-9,11,16}$

Isolated, PJA reached lower sensitivity, specificity, and accuracy than when combined with PTPB, despite presenting a lower specificity for diagnosing IATHA when compared with isolated PTPB (72\% vs. 90\%). Corroborating the results reported by Fink et al., we found PTPB to show greater sensitivity and accuracy values than PJA. ${ }^{16}$ However, our study has some limitations that preclude the interpretation of this finding, such as the lack of histopathological analysis of periprosthetic tissue, global and differential cell count, and leukocyte esterase strip test in the joint fluid - essential resources for the diagnosis of IATHA, especially in cases with negative culture.

Three of the analyzed hips showed the growth of Propionibacterium acnes, a pathogen known to present slow growth and low-virulence infections. ${ }^{17}$ We were able to identify the growth of this microorganism - which has already proved to be very important in periprosthetic infections - due to the fact that our cultures were incubated by up to 14 days under anaerobic conditions. ${ }^{12,17}$

According to the International Consensus on Periprosthetic Joint Infections (ICPJI), ${ }^{18}$ all suspected cases of IATHA must initially undergo synovial fluid analysis, reserving PTPB for inconclusive cases. In this sense, the ICPJI does not recommend the routine use of PTPB for investigating suspected prosthetic infection.

In theory, fine-needle PTPB and PJA involve the same risk for contamination, but while biopsy always obtains periprosthetic tissue, PJA sometimes fail in collecting sufficient material for laboratory analysis. Moreover, isolated PJA does not have good sensitivity to diagnose low-virulent microorganisms such as Propionibacterium acnes, verified in this study only by means of PTPB.

Although the literature advises against the use of PTPB in isolation, its sensitivity and accuracy for diagnosing IATHA increases when combined with PJA. ${ }^{9,18,19}$ On the other hand, the combination of both methods increase the total time of the procedure - a disadvantage overcame by the benefits offered by the use of PJA + PTPB presented in this article, specially regarding the identification of low-virulent microorganisms that form biofilms. ${ }^{19}$ 


\section{CONCLUSIONS}

PJA combined with PTPB was sensitive, specific, and effective in diagnosing periprosthetic hip infection, thus being an useful and indispensable tool for the proper planning of a revision hip arthroplasty. We expect that further randomized and multicenter studies confirm the findings of this study.

AUTHORS' CONTRIBUTIONS: Each author contributed individually and significantly to the development of this article. EA: writing of the article, review, statistical analysis, surgeries performance, analysis of the intellectual concept of the article, and preparation of the entire research project; MBCF: critical review of the article, analysis, and final approval; COGXL: analysis of the plates, statistical analysis, and idealization of the research project; ACMS: critical review of the article and analysis of intellectual content.

\section{REFERENCES}

1. Lucht U. The danish hip arthroplasty register. Acta Orthop Scand. 2000;71(5):433-9.

2. Beswick AD, Elvers KT, Smith AJ, Gooberman-Hill R, Lovering A, Blom AW. What is the evidence base to guide surgical treatment of infected hip prostheses? Systematic review of longitudinal studies in unselected patients. BMC Med. 2012;10:18.

3. Ince A, Rupp J, Frommelt L, Katzer A, Gille J, Lohr JF. Is "aseptic" loosening of the prosthetic cup after total hip replacement due to nonculturable bacterial pathogens in patients with low-grade infection? Clin Infect Dis. 2004;39(11):1599-603.

4. Della Valle CJ, Zuckerman JD, Di Cesare PE. Periprosthetic sepsis. Clin Orthop Relat Res. 2004;(420):26-31.

5. Yee DKH, Chiu KY, Yan CH, Ng FY. Review article: joint aspiration for diagnosis of periprosthetic infection. J Orthop Surg (Hong Kong). 2013;21(2):236-40.

6. Bauer TW, Parvizi J, Kobayashi N, Krebs V. Diagnosis of periprosthetic infection. J Bone Joint Surg Am. 2006;88(4):869-82.

7. Fink $B$, Grossmann $A$, Fuerst $M$, Schafer $P$, Frommelt $L$. Two-stage cementless revision of infected hip endoprostheses. Clin Orthop Relat Res. 2009;467(7): 1848-58.

8. Steinbrink K, Frommelt L. [Treatment of periprosthetic infection of the hip using one-stage exchange surgery]. Orthopade. 1995;24(4):335-43. German.

9. Williams JL, Norman P, Stockley I. The value of hip aspiration versus tissue biopsy in diagnosing infection before exchange hip arthroplasty surgery. $J$ Arthroplasty. 2004;19(5):582-6.
10. Ali F, Wilkinson JM, Cooper JR, Kerry RM, Hamer AJ, Norman P, Stockley I. Accuracy of joint aspiration for the preoperative diagnosis of infection in total hip arthroplasty. J Arthroplasty. 2006;21(2):221-6.

11. Costerton JW. Biofilm theory can guide the treatment of device-related orthopaedic infections. Clin Orthop Relat Res. 2005;(437):7-11.

12. Malhotra R, Morgan DA. Role of core biopsy in diagnosing infection before revision hip arthroplasty. J Arthroplasty. 2004;19(1):78-87.

13. Kilcoyne RF, Kaplan P. The lateral approach for hip arthrography. Skeletal Radiol. 1992;21(4):239-40.

14. Tande AJ, Patel R. Prosthetic joint infection. Clin Microbiol Rev. 2014;27(2):302-45.

15. Virolainen $P$, Lahteenmaki H, Hiltunen A, Sipola E, Meurman O, Nelimarkka O. The reliability of diagnosis of infection during revision arthroplasties. Scand $J$ Surg. 2002;91(2):178-81.

16. Fink B, Gebhard A, Fuerst M, Berger I, Schafer P. High diagnostic value of synovial biopsy in periprosthetic joint infection of the hip. Clin Orthop Relat Res. 2013;471(3):956-64.

17. Corvec S, Portillo ME, Pasticci BM, Borens O, Trampuz A. Epidemiology and new developments in the diagnosis of prosthetic joint infection. Int $\mathrm{J}$ Artif Organs. 2012;35(10):923-34.

18. Parvizi J, Gehrke T. Consenso internacional em infecções articulares periprotéticas. Batatais: AsBIO; 2014

19. Borens O, Nussbaumer F, Baalbaki R, Trampuz A. [Update on implant related infections in orthopaedic surgery: diagnosis and treatment]. Rev Med Suisse. 2009;5(230):2563-8. French. 